\title{
O TEMPO COMO UM TRAÇO DE UNIÃO ENTRE A SOCIEDADE E SUA HISTÓRIA
}

\author{
Ravena Olinda Teixeira ${ }^{1}$
}

Resumo: O presente texto é uma breve análise do conceito de tempo na qual pretendemos demonstrar que existem duas maneiras possíveis de ressignificá-lo dentro da filosofia espinosana. Em princípio, abordaremos o caráter ontológico desse conceito ressaltando que o tempo não passa de um produto da nossa imaginação e, por consequência, é possível interpretar Espinosa como um profundo crítico da ideia de tempo mensurável. Nessa perspectiva, o autor propõe aos homens que se libertem da percepção temporal, por meio de um processo de correção do intelecto, para compreender todas as coisas sob uma perspectiva da eternidade. No entanto, há outra possibilidade de leitura que garante ao tempo um papel mais significativo tanto na vida particular quanto na construção da sociedade, bem como na relação da mesma com a sua história, ou seja, com a evolução da consciência coletiva e com a manutenção do bem comum. Palavras-chave: tempo - tempo medido - tempo vivido - história - sociedade.

\section{Introdução}

"Nessa época feliz, na qual nada assinalava as horas, nada obrigava a contá las, e o tempo não possuía nenhuma medida além da distração e do tédio."

Rousseau, Ensaio sobre a origem das linguas, cap IX.

De início, vale ressaltar que a palavra tempo aparece poucas vezes nas obras de Espinosa, uma vez que esse conceito não é diretamente um dos problemas sobre os quais ele pretendia escrever. No entanto, para que, entre outras, a sua proposta de perceber o corpo e a mente sob certa perspectiva de eternidade fosse compreendida da maneira mais objetiva e prática possível, foi necessário que o autor dedicasse ao tempo algumas afirmações consideráveis.

O primeiro capítulo dos Pensamentos Metafísicos discorre sobre o ente real, o ente fictício e o ente de razão para tentar explicar os pontos mais obscuros da metafísica. ${ }^{2}$ Nessa análise, Espinosa nos diz que os entes fictícios e os entes de razão não são propriamente entes. Todavia, os entes fictícios e os entes de razão são distintos porque os entes de razão são mais úteis aos homens, no sentido de que servem para reter, explicar, e imaginar mais facilmente as coisas conhecidas. Ambos são modos de pensar, eles servem tanto para explicarmos as coisas (entes de razão - tempo, número e medida) quanto para imaginar as

\footnotetext{
${ }^{1}$ Doutoranda em Filosofia pela Universidade de São Paulo (USP). Bolsista CNPq. Orientador: Luís César Guimarães Oliva. E-mail: ravenaolinda@usp.br.

${ }^{2}$ Nesta obra, Espinosa se refere à tradição escolástica, herdeira de Aristóteles.
} 
coisas (entes de imaginação - cegueira, fim, término, etc.). Os entes de razão servem para explicar e os entes de imaginação, dentre os quais estão os entes fictícios, servem para imaginar. É nesse contexto que o tempo aparece como um dos modos de pensar que usamos para explicar as coisas, de forma semelhante ao número e à medida. Enquanto o número explica a quantidade discreta, a medida explica a quantidade contínua e o tempo explica a nossa duração. Portanto, Espinosa afirma que o tempo, por ser uma produção da mente, não representa nem um corpo exterior nem um estado do nosso corpo, ou seja, o tempo não é nem imagem nem afeto, por isso o tempo não pode ser definido como uma ideia, mas apenas como um ente de razão. Definindo o tempo enquanto ente de razão, Espinosa retira do tempo, fora de nossa mente, qualquer realidade substancial.

Todavia, a partir da Carta 12, escrita por Espinosa ao seu amigo Lodewijk Meyer no dia 20 de Abril de 1663, percebemos que seu pensamento filosófico mudou em relação aos conceitos de tempo e de duração, pois se nos Pensamentos Metafísicos, o tempo e a duração eram conceitos associados, já que o tempo era um ente que servia para explicar a duração, agora a duração não é mais considerada por ele como algo divisível e por isso o tempo é incapaz de mensurá-la. ${ }^{3}$ Assim, o tempo passa a ser chamado de ente de imaginação e na Ética o tempo jamais aparece na definição de duração ou na definição de eternidade. Com efeito, a Ética nos diz que é impossível ter um conhecimento adequado da duração quer seja do nosso corpo quer seja dos corpos exteriores:

E como, a partir desta propriedade comum das coisas singulares, demonstramos na Proposição precedente que não temos da duração do nosso corpo senão um conhecimento extremamente inadequado, logo, será de concluir o mesmo sobre a duração das coisas singulares, a saber, que dela não podemos ter senão um conhecimento extremamente inadequado. C. Q. D. (EIIP31D)

Por ser inadequado, o conhecimento da nossa duração não pode estar ao alcance do conhecimento racional, mas apenas da imaginação e, exclusivamente, por meio de um ente imaginário que chamamos de tempo. Entre outras coisas, Espinosa separa o tempo dos conceitos de eternidade e de duração para desarmar a superstição, uma vez que o medo do tempo é o fundador do poder teológico-político que opera no imaginário das pessoas como grilhões invisíveis que são quase indestrutíveis.

\footnotetext{
${ }^{3}$ No capítulo IV da primeira parte dos Pensamentos Metafísicos, sobre a duração e o tempo, Espinosa definia o tempo como ente capaz de explicar a duração: "Segue-se daí claramente que a duração não se distingue da inteira existência de uma coisa a não ser por razão. Com efeito, o quanto subtrais da duração de alguma coisa, o mesmo tanto é necessário subtrair de sua existência. Para determiná-lo, comparamos essa duração com a de outras coisas que têm movimento certo e determinado, e essa comparação chama-se tempo. Por isso o tempo não é uma afecção das coisas, mas apenas um mero modo de pensar, ou seja, como já dissemos, um ente de razão; é um modo de pensar, com efeito, que serve para explicar a duração."
} 


\section{A crítica ao tempo medido}

O caráter ontológico de não-ente dado ao tempo possibilita uma via de interpretação na qual Espinosa pode ser lido como um dos mais profundos críticos da noção que habitualmente temos do tempo. Embora ele não tenha escrito diretamente sobre isso, suas afirmações nos levam a perceber o quanto é nociva a noção de tempo que estamos acostumados a cultivar e a reproduzir.

Se pretendemos entender como a ideia de tempo atua no imaginário de grande parte das pessoas, vamos precisar retomar um pouco da mitologia grega e lembrar que nela o tempo era um Deus, ou melhor, um titã. Krónos era um titã poderoso. Segundo Pierre Vernant (2000), ele era o Deus da mentira e da falsidade, o primeiro soberano e o primeiro político, pois tudo o que fez foi pensando em manter o seu poder absoluto sobre todas as coisas. E quais coisas escapam ao poder do tempo? Somente as coisas metafísicas, porque todas as coisas corpóreas e finitas estão debaixo de seu poder, existindo dentro de seus limites. Como sabemos, Krónos devorava os próprios filhos e talvez seja por isso que nós damos ao tempo esse caráter corrosivo, que devora todas as coisas.

Por sua vez, os judeus interpretam o tempo como algo que é determinado: há tempo para todas as coisas e cabe ao homem, enquanto ser passivo, saber esperar o tempo certo de cada coisa. Pelas palavras de Salomão, há tempo de plantar, de colher, de edificar, há tempo para tudo debaixo do sol. E assim podemos compreender que o tempo é supostamente um ser que tem todos os acontecimentos em seu poder; embora não seja considerado um titã como para os gregos, o tempo para os judeus é algo que está nas mãos de Deus e que é moldado e modificado de acordo com a Sua vontade. Deus determina o tempo certo de cada coisa e o tempo de cada coisa já está determinado. Tais interpretações da ideia de tempo nos fazem perceber que tanto nos gregos quanto nos judeus e cristãos há uma espécie de medo do tempo. Talvez porque as duas interpretações apontem para uma mesma questão: o tempo destrói e corrói todas as coisas corpóreas, ele é senhor de todas as coisas finitas.

Espinosa reconhece o medo do tempo como um dos pilares da superstição. Afinal, ter medo do tempo faz parte do pensamento supersticioso, visto que por mais que os homens desconhecessem o seu futuro, o tempo de cada coisa já estava determinado. Para corroborar, cito Ericka Itokazu:

O medo do tempo é parceiro aliado do imaginário teológico-judaico-cristão, pois não é somente o tempo voraz e do esquecimento que tememos. A angústia amplia-se com a imposição da polaridade, em seu grau máximo,

\footnotetext{
${ }^{4}$ A distinção entre tempo medido e tempo vivido é feita por Ericka Marie Itokazu em Tempo, duração e eternidade na filosofia de Espinosa, tese de doutorado defendida em 2008 pela Universidade de São Paulo e disponível em http://www.teses.usp.br/teses/disponiveis/8/8133/tde-18032009-110714/pt-br.php. No entanto, o termo “tempo vivido" aparece em BOVE, La stratégie du conatus: affirmation et résistance chez Spinoza, p. 28.
} 
entre o sentimento do efêmero da criatura frente à eternidade do Criador transcendente, legislador e monarca do universo. ${ }^{5}$

Se Espinosa pretende libertar o homem das correntes psicológicas com as quais a superstição envolve a mente humana, há de se esforçar também por retirar do tempo essa imagem de um ser destruidor. E assim o faz, pois em uma filosofia da imanência em que não há abismo entre o infinito e o finito também não há espaço para um ser que, não sendo corpóreo, tem poder para agir e destruir todas as coisas corpóreas. A Ética II nos diz que todos os corpos agem e padecem de acordo com as leis que regem os próprios corpos, isto é, as leis da mecânica. Ou mesmo, não é coerente acreditar que o tempo de cada coisa já está determinado por um ser superior e que diante dele nos resta apenas a passividade, a paciência, o medo e a esperança de que o tempo nos seja sempre favorável.

Ademais, confundir o tempo com um ente real acarreta uma perspectiva da vida mais triste e impotente. Se antes o tempo era um Deus indomável ou se ele pertencia a Deus e por isso os homens deveriam temê-lo, nos nossos dias, em que somos remunerados por cada hora de trabalho, o tempo tem sido aliado da exploração humana. Seguindo uma ideia de tempo bem determinado, minuciosamente medido, cronometrado e calculado, vivem cada segundo baseados no relógio, por consequência, mais do que nunca a fala de Salomão faz sentido: há tempo de plantar, de colher, de edificar, de destruir. Nos dias de hoje, todas as coisas, todas as atividades humanas, estão sob a ordem de um tempo bem determinado, bem definido, e a máxima que reproduzimos diariamente é: "tempo é dinheiro", de tal forma que nos falta tempo para tudo, porque afinal toda vez que tentamos transformar o tempo em um ser real, ele nos escapa das mãos.

A filosofia de Espinosa nos revela uma nova perspectiva diante do tempo, ele passa a ser considerado como resultado da potência da mente e não da potência de um Deus transcendente, por isso o tempo não pode ser usado pela superstição como algo que transcende o homem e o determina, o modifica ou o limita; longe de ser um ente metafísico ou de ser um dos poderes e artimanhas de Deus para governar os homens, é para Espinosa, como bem define Itokazu, um "não-objeto". O tempo não é um ser sobrenatural nem tampouco é a medida da existência das coisas finitas, ele não é senão uma criação da mente humana, criação que frequentemente é confundida com os entes reais. O que quer dizer que, apesar de vivermos rodeados de relógios e calendários que servem para nos ajudar a administrar a nossa existência finita, nós nos baseamos em algo que não tem nenhuma realidade ontológica, senão enquanto um mero modo do pensar que existe apenas em nossa mente e que serve de auxílio para que a imaginação possa compreender a duração indefinida dos corpos. Portanto, o tempo é um conceito formado em nossa mente porque "sentimos e experimentamos" que nosso corpo é finito. Logo, o tempo é a forma que a nossa mente encontra para expressar a duração que ela percebe, se esforçando para quantificar uma

${ }^{5}$ ITOKAZU, E. Tempo, duração e eternidade na filosofia de Espinosa, p. 29. 
continuação indefinida do existir que é a sua própria potência finita. E assim, embora o tempo seja um esforço para compreender a duração, ele fracassa porque não é possível mensurá-la, uma vez que ela é a própria continuação indefinida da existência, continuação indivisível, conforme a Carta 12.

Sob a medição do tempo, a continuidade de nossa existência passa a ser vivida de forma esfacelada, porque o tempo não liga um instante a outro, ao contrário, ele os separa. Mas será possível encontrar no seio da filosofia espinosana um espaço para o tempo que não seja apenas como um ente que produz paixões tristes, uma vez que perceber o tempo é o que necessariamente possibilita que os homens tenham uma história, tanto individual quanto coletiva?

$\mathrm{E}$ aí cabe ressaltar uma distinção entre o tempo vivido e o tempo medido e perceber que o tempo medido é apenas uma ilusão que limita o que realmente importa: o tempo vivido.

\section{O tempo vivido: memória, história e sociedade.}

O que chamamos de tempo vivido é justamente as afecções do corpo, suas modificações, seus vestígios, suas marcas e suas imagens. Nós percebemos a duração por causa da passagem entre um afeto e outro, ou seja, por causa dos vestígios que são deixados em nosso corpo. Com efeito, o tempo vivido é o conjunto das experiências que nos compõem e que aos poucos vão modelando a nossa identidade pessoal e a nossa história. Logo, podemos dizer que o tempo vivido é a memória.

Tanto a memória individual quanto a memória coletiva constituem e são constituídas pela experiência, há entre elas (memória e experiência) uma relação de dependência. De forma que não há memória sem experiência e tampouco nossas experiências seriam úteis se não tivéssemos capacidade de gravá-las na memória. (Quando Espinosa, na EIIP18, descreve como se dá o processo de recordar os corpos exteriores, entendemos que a memória é o resultado das experiências de nosso corpo e da nossa mente, e que podemos considerar a experiência como um conhecimento válido porque além de experimentar as coisas nós podemos memorizá-las e compará-las.)

Para Espinosa existem apenas duas maneiras de chegar à verdade: pelo conhecimento racional e pela experiência (se considerarmos que a experiência pode ensinar algo de verdadeiro), uma vez que, em todas as suas obras, encontramos sua insistência em dizer que não podemos duvidar daquilo que a experiência nos diz. Com efeito, acreditamos, por conta dessa insistência, que é justamente por defender a experiência como um meio de alcançar princípios verdadeiros que no Tratado político, no qual ele analisa as formas de governo e procura estabelecer princípios para uma república “ideal”, notamos que logo após as seguintes palavras: "conforme a experiência demonstra", encontramos algum fato histórico que comprove suas hipóteses, assim como encontramos frequentemente referências aos grandes historiadores, por exemplo, Tito Lívio e Tácito. No Tratado político, 
vemos claramente que o filósofo retira princípios políticos dos exemplos históricos. Vejamos:

Nenhum rei, além disso, poderá proporcionar a si mesmo maior segurança do que aquele que reina assim na cidade. [...] Quanto menos são os conselheiros e, por conseguinte, quanto mais potentes são, maior é para o rei o perigo de que eles transfiram o estado para um outro. Certamente, nada aterrorizou mais David que o fato de o seu conselheiro Aquitofel escolher o partido de Absalão. [...] Tácito, Histórias, Livro I. ${ }^{6}$

Ou seja, sempre que Espinosa quer declarar a autoridade da experiência ele recorre à história, logo a história também é reconhecida como um critério legítimo que serve não só para conhecer os fatos que ocorreram no passado, mas para extrair dela algo que nos ajude a compreender o presente e estabelecer princípios que proporcionem um futuro mais seguro. Tais coisas ficam ainda mais claras no Tratado Teológico-político (TTP). Cito:

O que a escritura quer ensinar de natureza apenas especulativa é, essencialmente, o seguinte: existe um Deus, ou seja, um ser que fez, dirige e sustenta todas as coisas com suma sabedoria, que cuida dos homens, ou melhor, daqueles que vivem piedosa e honestamente, já que aos outros ele castiga com numerosos suplícios e os aparta dos bons. Tudo isso a escritura comprova apenas pela experiência, quer dizer, pelas histórias que narra. ${ }^{7}$

Em seguida, ele encerra esse mesmo capítulo ao afirmar que aquele que ignora as histórias das Sagradas escrituras e não conhece nada pela luz natural (razão), se não é ímpio ou insubmisso com certeza é desumano, semelhante a um animal que não possui nenhum dom de Deus.

Nessa mesma obra (TTP), Espinosa faz uma análise da história dos hebreus para propor uma nova política, uma política sem a interferência da religião. Durante todo o texto, percebemos claramente como ele recorre à história principalmente para compreender as origens da superstição e para separar a religião e o Estado. De acordo com a análise histórica feita por Espinosa nessa obra, compreendemos como se originam as superstições judaicocristãs, como a religião foi utilizada como meio para governar a multidão e por quais meios ela mantém esse poder até os dias atuais. Assim, vemos que Espinosa retira princípios políticos verdadeiros da experiência (história). O capítulo XVIII do TTP já traz no título a comprovação de nossas palavras, a saber, Onde se concluem, a partir da república dos hebreus, e da sua história, alguns princípios politicos.

${ }^{6}$ ESPINOSA, B. Tratado politico, cap. VII, $\$ 14$.

${ }^{7}$ ESPINOSA, B. Tratado Teológico-político, cap. V, p. 199 e 200. 
Além disso, percebemos que o tempo vivido e a memória coletiva, no caso principalmente dos hebreus, foi, e continua sendo até hoje, um elo entre eles desde o princípio, na formação do Estado, que para Espinosa acontece logo depois da saída do Egito. Eles partilhavam e partilham das mesmas memórias e por isso formam um novo corpo, que com a formação do Estado veio a ser um corpo político. Nas palavras de Laurent Bove:

Os hebreus assim definem sua identidade no imaginário, atribuindo-se, com exclusividade, o nome de filios Dei. Esta identidade é a de um povo, da história mítica de uma nação que, para além dos indivíduos mortais que a compunham, afirma-se na sua substância imaginária como indestrutível e eterna. $^{8}$

No Tratado político, Espinosa defende que os homens são naturalmente sociáveis e que não é possível pensar nos homens vivendo isoladamente. Afinal, nada é tão bom para o homem quanto outro homem e por isso eles jamais farão nada que dissolva o estado civil por completo. Mas quais fatores são determinantes para a formação desta ou daquela sociedade?

\section{Considerações finais}

Espinosa não escreve sobre isso de maneira direta, mas ao lermos o Tratado Teológicopolítico somos conduzidos a pensar que o tempo vivido e a memória são o elo entre a sociedade e sua história, e que tal elo está registrado, no caso da sociedade formada pelos hebreus, nas Escrituras Sagradas. O tempo vivido dos primeiros hebreus e daqueles que fundaram o primeiro Estado de Israel está reunido exclusivamente nas Sagradas Escrituras e compõe nessa obra a história desse povo específico, sendo ela mesma o único elo entre eles, ou seja, tais registros são o elo entre essa sociedade e sua história. De tal forma que sem eles, sem tais afecções em comum, certamente esse povo jamais teria se formado tal como aconteceu e nós não teríamos por meio deles ou de tantos outros povos como extrair princípios políticos que nos ajudassem a resolver questões que permanecem latentes nos dias de hoje. Desse modo, o tempo pode ser visto como uma produção que não resulta apenas na impotência humana e nas paixões tristes, mas também em um conhecimento verdadeiro que tem como fundamento a própria experiência. É a partir do tempo vivido que surgem e são registradas as experiências humanas. Portanto, é por esse prisma que o tempo, assim como a própria imaginação, embora sejam um modo limitado e parcial de perceber as coisas, podem produzir um conhecimento verdadeiro. Para tanto, nos ensina a Ética II, basta que estejamos conscientes de suas limitações.

${ }^{8}$ BOVE, L. La stratégie du conatus: affirmation et résistance chez Spinoza, p. 200. Tradução nossa. 


\section{TIME AS A TRACE OF UNION BETWEEN SOCIETY AND ITS HISTORY}

Abstract: This paper is a brief analysis of the concept of time in which we intend to demonstrate that there are two possible ways of offering it new significance inside Spinoza's philosophy. In principle, we discuss the ontological character of this concept emphasizing that time is nothing but a product of our imagination and, consequently, it is possible to interpret Spinoza as a deep critic of the idea of measurable time. From this perspective, the author proposes to release men from the temporal perception through a process of correction of the intellect, in order to understand all things from the perspective of eternity. However, there is another possibility of interpretation that guarantees to time a more significant role both in private life and in the construction of society, as well as in the relation of society with its history, i.e. with the evolution of the collective consciousness and the maintenance of common good.

Keywords: time - measured time - lived time - history - society.

\section{REFERÊNCIAS BIBLIOGRÁFICAS}

BOVE, L. La stratégie du conatus: affirmation et résistance chez Spinoza. Paris: Vrin, 1996.

CHAUI, M. A nervura do real: Imanência e liberdade em Espinosa. São Paulo: Companhia das Letras, 1999.

Da realidade sem mistérios ao mistério do mundo: Espinosa, Voltaire, Merleau-Ponty. São Paulo: Brasiliense, 1999.

ESPINOSA, B. Correspondência. São Paulo: Abril Cultural, 1973.

- Pensamentos metafísicos. Tradução e notas de Marilena Chaui. São Paulo: Abril Cultural, 1973.

. Tratado político. São Paulo: Abril Cultural, 1973.

. CEuvres Complètes. Bibliothèque de la Plêiade. Paris: Gallimard, 1978.

- Correspondencia. Traducción, prólogo y notas de Atilano Domínguez. Madrid: Alianza Editorial, 1988.

- Tratado Breve. Traducción, prólogo y notas de Atilano Domínguez. Madrid: Alianza Editorial, 1990.

. Tratado da reforma da inteligência. São Paulo: Martins Fontes, 2004.

. Tratado Teológico-politico. Tradução, introdução e notas de Diogo Pires Aurélio. $3^{\mathrm{a}}$ edição. Lisboa: Imprensa Nacional-Casa da Moeda, 2004.

. Ética. Belo Horizonte: Autêntica Editora, 2008. 
ITOKAZU, E. Tempo, duração e eternidade na filosofia de Espinosa. Tese de doutorado. Departamento de Filosofia da Universidade de São Paulo, 2008.

ROUSSEAU, J. Ensaio sobre a origem das línguas. São Paulo: Abril Cultural, 1978.

SALOMÃO. Eclesiastes. In: Bíblia Sagrada. $2^{a}$ ed., revista e atualizada no Brasil. São Paulo: Ed. SBB, 2007.

TEIXEIRA, L. A doutrina dos modos de percep̧cão e o conceito de abstração na filosofia de Espinosa. São Paulo: UNESP, 2001.

VERNANT, P. O universo, os deuses, os homens. São Paulo: Cia das Letras, 2000. 